\title{
Effect of the CS-UCS interval on the acquisition of an avoidance response and on its subsequent extinction through massing of trials ${ }^{1}$
}

\begin{abstract}
PETER G. JAFFE and MORRIE BAUM, McGill University, Montreal, Canada
\end{abstract}

Female hooded rats were trained to avoid shock by jumping onto a ledge in an automated avoidance box. The animals were divided into three groups (each having $N=10$ ) receiving CS-UCS intervals of 5 , 17.5 , and $30 \mathrm{sec}$. After attaining a learning criterion of 10 consecutive avoidances, Ss began extinction with the shocker disconnected. In order to hasten extinction, trials were massed for all three groups. Rats in the 5-sec CS-UCS interval group differed significantly from the other two in taking longer to learn the avoidance response and requiring more trials to extinguish. All groups differed from each other in the mean latency of avoiding during the criterial run.

Studies of the trace-avoidanceconditioning procedure show that as the time lapse between the CS and UCS increases, animals have a more difficult time in acquiring the avoidance response (Warner, 1932; Kamin, 1954; Brush, Brush, \& Solomon, 1955). Other studies have shown no such trend (Black, 1963; Black \& Richards ${ }^{2}$ ). Studies centering around the CS-UCS interval's involvement in delayed conditioning have shown both no effect of this parameter (Church, Brush, \& Solomon, 1956) and two different kinds of effects. A U-shaped function of initial improvement in acquisiton and subsequent deterioration as the CS-UCS interval was increased (Black, 1963) and a monotonic linear function of decreased acquisition difficulty with lengthened intervals have been reported (Schwartz, 1958; Pearl \& Edwards, 1963; Bolles, Warren, \& Ostrov, 1966). The present study sought to determine the effects of the CS-UCS interval on the learning of a novel avoidance response.

Another interesting feature of the CS-UCS interval may be its effect on extinction. Finding methods that hasten extinction is important due to the possibility that analogous techniques may be used on anxiety-motivated behavior in man (e.g., in behavior therapy). One such technique is called massing of trials. This procedure involves shortening the intertrial interval to a few seconds, which usually leads to the rapid extinction of the response (Baum \& Oler, 1968; Oler \&
Baum, 1968; Best \& Baum, in press). The present study also sought to investigate further the facilitation of extinction of an avoidance response through massing of trials by exploring the effect of a new parameter, the CS-UCS interval.

\section{SUBJECTS}

Thirty experimentally naive hooded female rats, obtained from the Canadian Breeding Farm and weighing between 160 and $200 \mathrm{~g}$, served as Ss. All animals were maintained on ad lib food and water schedule and appeared to be in good health all through the experiment.

\section{APPARATUS}

The apparatus used was entirely automated and was identical to that described extensively in previous studies (Baum, 1965, 1966). Briefly, it consisted of a large plywood-and-Plexiglas box fitted with a grid floor through which scrambled electric shock could be administered. The shock was set at $0.5 \mathrm{~mA}$ on the commercially built shock source (Grason-Stadler Model 1064GS). Into one side of the cube-shaped box projected a $2 \frac{1}{2}$-in.-wide safety ledge. The rat could escape or avoid shock by jumping or climbing onto the ledge where its presence was detected by a photocell system. The safety ledge was automatically retractable via an electric motor device. A quick retraction of the ledge resulted in the rat's tumbling to the grid floor.

\section{PROCEDURE}

Without prior habituation to the apparatus, each rat was dropped onto the grid floor via the sliding ceiling. Five, 17.5, or $30 \mathrm{sec}$ after the rat had landed on the grid floor (according to which one of the three experimental groups the animal had been randomly assigned to), the grid was electrified, and $\mathrm{S}$ received foot-shock until it escaped by jumping or climbing onto the safety ledge. The rat was permitted to remain on the ledge for $30 \mathrm{sec}$ (the intertrial interval), after which time the ledge was automatically retracted, causing $\mathrm{S}$ to fall to the grid floor and starting the next training trial. The rat had the opportunity throughout training to avoid the shock by jumping or climbing back onto the safety ledge immediately after having been knocked down and before the expiration of the CS-UCS interval. Each rat was trained until it attained a learning criterion of 10 consecutive avoidance responses (i.e., 10 consecutive response latencies shorter than the CS-UCS interval). There was no discrete CS employed. The cue of being dropped onto the grid floor was the effective CS.

Immediately after $S$ attained the learning criterion, the shocker was disconnected by $E$ and the extinction procedure commenced. Extinction was identical for all three groups that had undergone different CS-UCS intervals during acquisition. It consisted of shortening the intertrial interval from $30 \mathrm{sec}$ to $3 \mathrm{sec}$ and thereby massing trials. Each $S$ was run until it attained an extinction criterion of 5 consecutive minutes on the grid floor without an avoidance response.

\section{RESULTS}

The acquisition and extinction data for the three groups of rats are summarized in Table 1. In acquisition, a Kruskal-Wallis one-way analysis of variance by ranks (Siegel, 1956) revealed a significant effect of the various CS-UCS intervals on four different measures. Group $5 \mathrm{sec}$ took significantly longer to make its first avoidance response than did Group $17.5 \mathrm{sec}$ or Group $30 \mathrm{sec}(U=25$, $.05<\mathrm{p}<.10$ and $U=19, \mathrm{p}<.02$, respectively), received more shocks than did Group $17.5 \mathrm{sec}$ or Group $30 \mathrm{sec}$ $(U=25, .05<p<.10$ and $U=20$, $\mathrm{p}<.05$, respectively), and required more trials to attain the avoidance-learning criterion than did Group $17.5 \mathrm{sec}$ or Group $30 \sec (U=20, p<.05$ and $U=21$, $p<.05$, respectively). There were no significant differences between Group $17.5 \mathrm{sec}$ and Group $30 \mathrm{sec}$ on these acquisition measures. In mean response latencies during the criterial run of 10 consecutive avoidances, those of Group $5 \mathrm{sec}$.were significantly shorter than were those of Group $17.5 \mathrm{sec}$ or Group $30 \mathrm{sec}(U=0, p<.002$ for both comparisons). Group $30 \mathrm{sec}$ had latencies that averaged to almost twice those of Group $17.5 \sec (U=10, p<.002)$. All of the above statistical comparisons made use of a two-tailed Mann-Whitney $U$ test (Siegel, 1956).

The Kruskal-Wallis test also showed that the effect of the CS-UCS interval on extinction through massing of trials was significant. The primary index of the speed of extinction was taken to be the number of trials required to reach the criterion of 5 consecutive minutes on the grid floor without an avoidance response. Group 5 sec took significantly longer than Group $17.5 \mathrm{sec}$ or Group $30 \mathrm{sec}$ to reach this extinction level $(U=9, p<.002$ and $\mathrm{U}=14, \mathrm{p}<.02$, respectively), although the two latter groups of longer CS-UCS intervals did not differ in this measure to any significant extent $(U=35, p>.10)$. 
Table 1

Summary of the Acquisition and Extinction Results. Groups 5 sec, $17.5 \mathrm{sec}$, and 30 sec received CS-UCS intervals of $5,17.5$, and $30 \mathrm{sec}$ during avoidance acquisition.

\begin{tabular}{|c|c|c|c|c|}
\hline & $\begin{array}{l}\text { roup } 5 \mathrm{Sec} \\
(\mathrm{N}=10)\end{array}$ & $\begin{array}{c}\text { Group } 17.5 \mathrm{Sec} \\
(\mathrm{N}=10)\end{array}$ & $\begin{array}{l}\text { Group } 30 \text { Sec } \\
(N=10)\end{array}$ & Kruskal-Wallis H \\
\hline $\begin{array}{l}\text { Median trial of the first } \\
\text { avoidance response. }\end{array}$ & 5.0 & 3.0 & 3.0 & $\mathrm{H}=10.99, \mathrm{p}<.01$ \\
\hline $\begin{array}{l}\text { Median number of shocks } \\
\text { received in acquisition }\end{array}$ & 6.5 & 4.5 & 3.0 & $H=6.99, p<.05$ \\
\hline $\begin{array}{l}\text { Median trial of the tenth } \\
\text { consecutive avoidance } \\
\text { in acquisition }\end{array}$ & 23.5 & 15.5 & 15.0 & $\mathrm{H}=6.64, \mathrm{p}<.05$ \\
\hline $\begin{array}{l}\text { Median mean avoidance } \\
\text { latency in the criterial } \\
\text { run (sec) }\end{array}$ & 1.7 & 3.7 & 7.1 & $\mathrm{H}=34.35, \mathrm{p}<.001$ \\
\hline $\begin{array}{l}\text { Median number of responses } \\
\text { in massed-trial extinction }\end{array}$ & 12.0 & 5.5 & 6.5 & $\mathrm{H}=12.48, \mathrm{p}<.01$ \\
\hline
\end{tabular}

\section{DISCUSSION}

The present study is somewhat complex in nature as the CS is not as clearly defined as in previous studies and falls under both the trace- and delayed-conditioning paradigms. From the trace-conditioning viewpoint, one could say that the CS was the cue for the rat of being grounded by the retractable ledge. However, if one were to consider environmental cues as fundamental, the CS would be the grid floor itself. This CS would terminate only with an avoidance response and would coincide with the UCS termination, fitting the definition of the delayed-conditioning model. The present findings of a greater ability to acquire an avoidance response for the longer CS-UCS interval groups agrees with only some of the delayed-conditioning results but totally contradicts the research on trace-avoidance conditioning. The present conditioning method used is perhaps an interaction of the two procedures with the delayed-conditioning-stimulus complex having a greater effect.

The results of the acquisition data can be interpreted in terms of the two-process theory of avoidance learning, as outlined by Mowrer (1947) and elaborated by Solomon \& Wynne (1953). Briefly, this theory states that underlying avoidance learning lies both the classically conditioned emotional response and the instrumentally conditioned response. By simple conditioning principles, the magnitude of the emotional response to the CS diminishes as the CS-UCS interval is lengthened. Interacting with this fear is the opportunity to make a successful avoidance response rather than an escape. This probably increases as the CS-UCS interval is stretched. Thus, rats in Group $5 \mathrm{sec}$ find themselves with a better conditioned fear but less opportunity to avoid than those Ss that compose Group $17.5 \mathrm{sec}$ and Group $30 \mathrm{sec}$. Black and Richards ${ }^{2}$ explained the lack of any significant differences among their rats in various CS-UCS intervals in terms of an interaction between these two functions. In this study, however, the opportunity to avoid must have been of primary importance in acquisition as Group $5 \mathrm{sec}$ took significantly longer to make its first avoidance and to reach the acquisition criterion.

As noted in Table 1, Group 5 sec took significantly longer to extinguish than the two other experimental groups. One possible explanation for this is the fact that this group had received more shocks during avoidance training and, consequently, found it harder to undergo extinction. The persistence of the avoidance response by Ss in Group $5 \mathrm{sec}$ could be interpreted in another way. The quicker onset of the UCS led to a greater anxiety in this group and, subsequently, to a greater anxiety reduction for each avoidance. The greater reinforcement of the avoidance meant an increased probability of its reoccurrence and, thus, more resistance to extinction.

\section{REFERENCES}

BAUM, M. An automated apparatus for the avoidance training of rats. Psychological Reports, 1965, 16, 1205-1211.

BAUM, M. Rapid extinction of an avoidance response following a period of response prevention in the avoidance apparatus. Psychological Reports, 1966, 18, 59-64.

BAUM, M., \& OLER. I. D. Comparison of two techniques for hastening extinction of avoidance-responding in rats. Psychological Reports, 1968, 23, 807-813.

BEST, J. K., \& BAUM, M. Studies of the extinction of avoidance responding through the massing of trials. Canadian Journal of Psychology, in press.

BLACK, A. H. The effects of CS-UCS interval on avoidance conditioning in the rat. Canadian Journal of Psychology, 1963, 17, 174-182.

BOLLES, R. C., WARREN, JR., J. A., \& OSTROV, N. The role of the CS-UCS interval in bar press avoidance learning. Psychonomic Science, 1966, 6, 113-114.

BRUSH, F. R., BRUSH, E. L., \& SOLOMON, R. L. Traumatic avoidance learning: The effects of CS-US interval with a delayed-conditioning procedure. Journal of Comparative \& Physiological Psychology, 1955, 48, 285-293. CHURCH, R. M., BRUSH, I. R., \& SOLOMON, R. L. Traumatic avoidance learning: The effects of CS-US interval with a delayed conditioning procedure in a free responding situation. Journal of Comparative \& Physiological Psychology, 1956, 49, 301-308.

KAMIN, L. J. Traumatic avoidance learning: The effects of CS-US interval with a trace-conditioning procedure. Journal of Comparative \& Physiological Psychology, 1954, 47, 65-72.

MOWRER, O. H. On the dual nature of learning. Harvard Education Review, 1947, Spring, 102-148.

OLER, I. D., \& BAUM, M. Facilitated extinction of an avoidance response through shortening of the inter-trial interval. Psychonomic Science, 1968, 11, 323-324.

PEARL, J., \& EDWARDS, R. E. Delayed avoidance conditioning: Warning stimulus (CS) duration. Psychological Reports, 1962, 11, 375-380.

SCHWARTZ, M. Conditioned stimulus variables in avoidance learning. Journal of Experimental Psychology, 1958, 55, 347-351.

SIEGEL, S. Nonparametric statistics for the behavioral sciences. New York: McGraw-Hill, 1956.

SOLOMON, R. L., \& WYNNE, L. C. Traumatic avoidance learning: Acquisition in normal dogs. Psychological Monographs, 1953, 67(4, Whole No. 354).

WARNER, L. H. The association span of the white rat. Journal of Genetic Psychology, $1932,41,57-90$

\section{NOTES}

1. This research was supported by a grant (No. APA-253) to Morrie Baum from the National Research Council of Canada.

2. Black, A. H., \& Richards, M. The effects of CS-UCS interval on trace avoidance conditioning in the rat. Unpublished manuscript, 1966. 